\title{
FORMAÇÃO DE LEITORES E USO DE BLOGS: UMA PROPOSTA DE ENSINO
}

\author{
TRAINING READERS AND THE USE OF BLOGS: A PROPOSAL TO TEACH IN \\ A TECHNOLOGICAL AGE
}

\author{
FORMACIÓN DE LECTORES Y USO DE BLOGS: UNA PROPUESTA DE \\ ENSEÑANZA
}

\author{
Laísa Veroneze Bisol ${ }^{1}$, Andiara Zandoná ${ }^{2}$, Ana Paula Teixeira Porto ${ }^{3}$
}

\section{RESUMO}

Este trabalho consiste no estudo da formação de leitores, considerando as diversas possibilidades que existem hoje no que diz respeito a tecnologias, em especial, ferramentas de comunicação multimídia. Esta pesquisa é realizada a partir de revisão bibliográfica e, ainda, considerando um relato de experiência das autoras, que propuseram como atividade avaliativa de uma disciplina ministrada para o curso de Letras da Universidade Regional Integrada do Alto Uruguai e das Missões, a confecção de blogs como forma de estimular a leitura de obras de leitores consagrados na literatura brasileira. A fundamentação está baseada em proposições de Wilson de Pádua Paula Filho, Elisabeth Saad Corrêa, Maria João Gomes, Joseane Maia e outros estudiosos do tema. Através desta pesquisa é reafirmada a necessidade da utilização das ferramentas tecnológicas e multimidiáticas disponíveis atualmente a fim de formar professores que deverão transmitir informações aos seus alunos de forma mais atrativa e interativa.

PALAVRAS-CHAVE: Formação de leitores. Comunicação multimídia. Blog. Tecnologias. Interatividade.

\section{ABSTRACT}

This paper is about the study of readers formation, considering the various possibilities that have today related to technologies, especially, multimedia communication implement. This research is realized from

\footnotetext{
${ }^{1}$ Jornalista (UFSM). Mestre em Letras - Literatura Comparada (URI). Doutoranda em Letras - Estudos Literários (UFSM).

${ }^{2}$ Graduada em Letras Inglês Português e suas respectivas Literaturas pela Universidade Regional Integrada do Alto Uruguai e das Missões - URI Campus de Frederico Westphalen. Professora da Rede Municipal de ensino no município de Cerro Grande, RS. Mestre em Letras pela Universidade Regional Integrada do Alto Uruguai e das Missões - URI - Campus de Frederico Westphalen. Além disso, Especialista em Língua e Cultura Inglesa na mesma instituição.
}

${ }^{3}$ Possui graduação em Letras pela Universidade Federal de Santa Maria (2002), Especialização em Educação a Distância pela Pontifícia Universidade Católica do Rio Grande do Sul (2012), Mestrado em Letras (2005) e Doutorado em Letras (2011) pela Universidade Federal do Rio Grande do Sul, na área de Literatura Brasileira. 


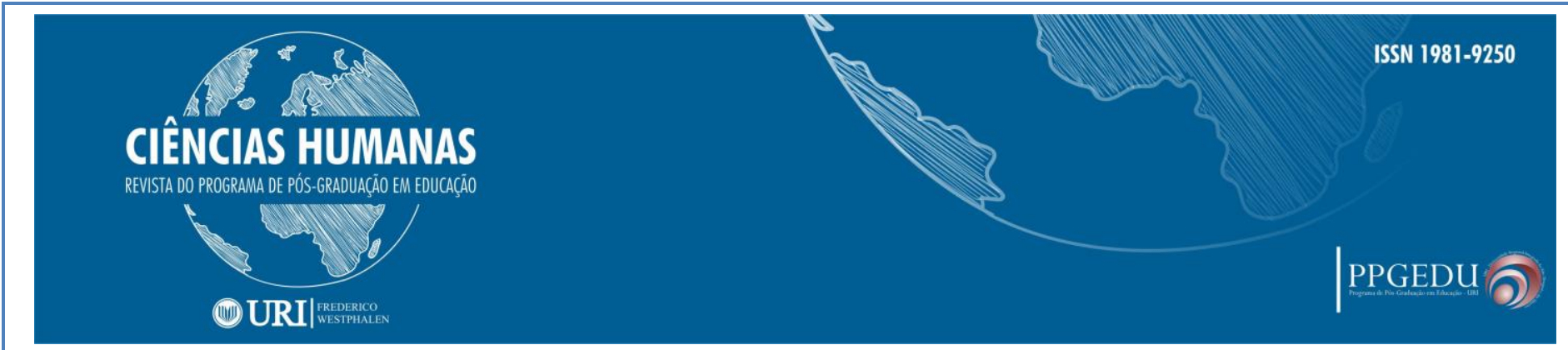

literature review and, yet, considering an experience report of authors, that proposed as evaluative activity of a discipline given to the Letters' course of University, the confection of blogs as a way to stimulate the reading of books by enshrined authors in Brazilian literature. The grounding is based in propositions of Wilson de Pádua Paula Filho, Elisabeth Saad Corrêa, Maria João Gomes, Joseane Maia and other students of the subject. With this research is reaffirmed the necessity of use of technological implements and multimediatic available nowadays to form teachers which should transmit information to their students more attractive and interactive way.

KEYWORDS: Readers formation. Multimedia communication. Blog. Technologies. Interactivity.

\section{RESUMEN}

Este trabajo consiste en el estudio de la formación de lectores, considerando las diversas posibilidades que existen hoy en lo que se refiere a tecnologías, en especial, herramientas de comunicación multimedia. Esta investigación es realizada a partir de revisión bibliográfica y, aún, considerando un relato de experiencia de las autoras, que propusieron como actividad evaluativa de una disciplina ministrada para el curso de Letras de la Universidad Regional Integrada del Alto Uruguay y de las Misiones, la confección de blogs como forma de estimular la lectura de obras de lectores consagrados en la literatura brasileña. La fundamentación está basada en proposiciones de Wilson de Padua Paula Filho, Elisabeth Saad Corrêa, Maria João Gomes, Joseane Maia y otros estudiosos del tema. A través de esta investigación se reafirma la necesidad de la utilización de las herramientas tecnológicas y multimedia disponibles actualmente para formar profesores que deberán transmitir informaciones a sus alumnos de forma más atractiva e interactiva.

PALABRAS CLAVE: Formación de lectores. Comunicación multimedia. Blog. Tecnologías. La interactividad.

Em um tempo permeado por tudo o que envolve tecnologias e suas ferramentas, o estímulo pela leitura ou pela procura do conhecimento daquilo que não faz parte deste meio configura-se como um grande desafio para os educadores. Não somente nas salas de aula de ensino fundamental ou médio, mas especialmente nas instituições de ensino superior, é que se torna imprescindível o pensar em novos métodos, em soluções que aliem o conteúdo a ser ministrado com a tecnologia disponível hoje.

Formar professores nesta perspectiva, utilizando as ferramentas disponíveis para demonstrar novos métodos, configura-se também como uma forma de estimular que os novos docentes utilizem estas práticas com os estudantes que poderão ser mais atraídos pela leitura, quando puderem aliar o processo de aprendizagem com as possibilidades tecnológicas disponíveis.

Essa mudança na didática dos professores é apontada por Adriano Vargas Freitas e Lígia Silva Leite, no artigo "Capacitação de professores na sociedade contemporânea: obstáculos e desafios" (2008). Os autores argumentam que os professores precisam se 


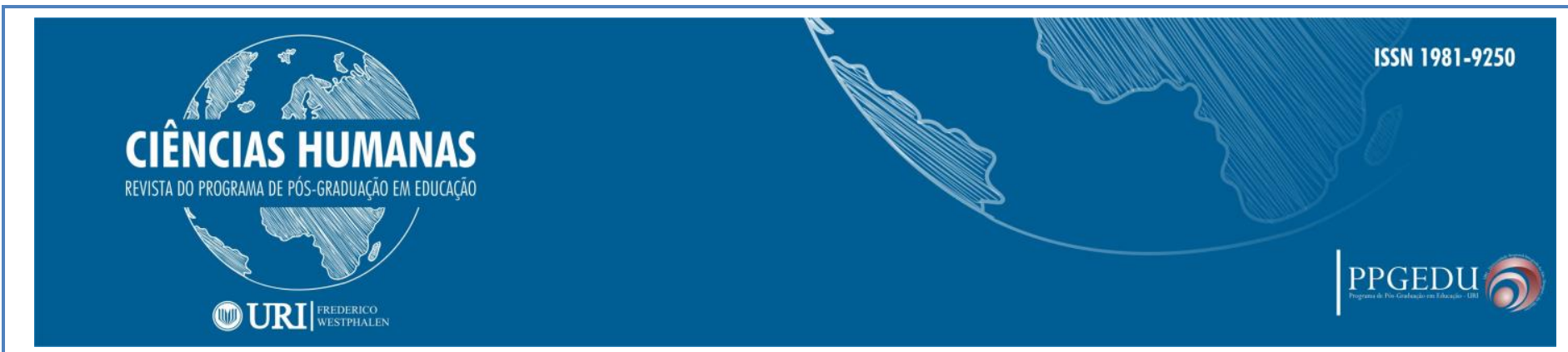

"alfabetizar tecnologicamente", a partir de subsídios que facilitem a sua capacitação de aprender a utilizar esses recursos que fazem parte do mundo globalizado.

O computador, assim, deixa de ser um objeto de consumo para servir como auxiliar dos professores em sala de aula. Entretanto, os autores ponderam que é preciso haver alterações nas políticas educacionais para que não apenas o professor seja $o$ responsável por essa mudança e sinta-se guiado de alguma forma nessa tarefa que se apresenta como novidade e necessidade na busca por uma educação mais completa e de melhor qualidade.

O grande questionamento seria, portanto: de que forma utilizar estas tecnologias a favor da formação docente, com vistas a conceber uma melhoria no processo de constituição de leitores críticos? E, ainda, em que medida ferramentas disponíveis hoje podem auxiliar neste processo? Embora essa discussão já tenha sido bastante desenvolvida no âmbito acadêmico é preciso considerar que existem regiões, especialmente no interior dos estados brasileiros, que a expansão tecnológica ainda não se dá de forma tão natural quanto em outros locais. Dessa maneira, ainda é importante pensarmos em formas de utilizar as tecnologias considerando as realidades diversas, ou seja, levar a tecnologia e as ferramentas multimídia para a sala de aula, mesmo partindo de possibilidades mais restritas.

A comunicação multimidiática se dá através de uma mídia estática (os mais diversos tipos de textos ou fotografia) aliada com uma outra dinâmica (áudio, vídeo, som), isso tudo marcado justamente pela interatividade, pela possibilidade de o receptor da informação voltar a ter contato com ela e, ainda, fazer parte através da expressão de sua opinião.

O comunicador estudioso no assunto Wilson de Pádua Paula Filho (2001) aborda a ferramenta multimídia como não-linear, oferecendo a possibilidade de consulta, pesquisa e atualização da base de dados audiovisuais. Além disso, abrange a geração de material em tempo real. A partir destas considerações, podemos reafirmar o porquê esta forma de abordar os conteúdos podem se tornar mais atrativas àqueles que irão recebêlo. A não-linearidade permite, por exemplo, o acesso a um vídeo explicativo de forma que o receptor possa clicar na opção "pause" para parar em um dado momento, 


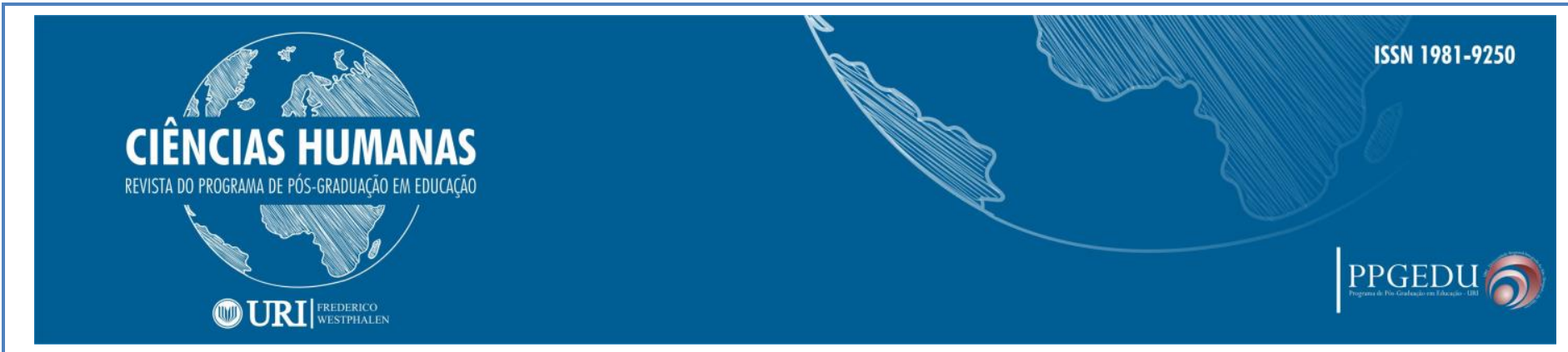

antecipar as imagens de acordo com o interesse ou, ainda, voltar a um ponto que deseja visualizar novamente. Além disso, quando postado na internet, muitas vezes são abertas possibilidades ainda maiores de interatividade, quando o espectador pode, inclusive, deixar comentários a respeito do assunto exibido no material audiovisual.

Ao conceber a comunicação através de ferramentas multimidiáticas, o mesmo autor trata a respeito do tempo real. Isto quer dizer, na época em que adolescentes, jovens e adultos estão inseridos nas mais diferentes redes sociais, com atualizações constantes e imediatas das mais diferentes fontes. Esta é uma alternativa muito atrativa aos apreciadores de imediatismo e interação, visto que neste espaço virtual de troca de informações, tudo é atualizado todo o tempo.

Aliar as possibilidades disponibilizadas através das ferramentas que permitem uma comunicação multimidiática, com a tecnologia e a possibilidade gratuita de atualização imediata pode se tornar uma maneira eficaz de produção e transmissão de conteúdo.

Fotografar, fazer slide-show unindo imagens com legendas, gravar um áudio ou mesmo um vídeo e, montar com outras informações de texto e trilha sonora, são possibilidades realizadas facilmente e sem custos, com a utilização de poucos instrumentos, como celular e computador. O contato com estes materiais, mesmo que produzidos de forma amadora, acaba tornando-se mais atrativo aos receptores de informações do que, por exemplo, simplesmente ler um texto estático sobre determinados assuntos. Elisabeth Saad Corrêa (2009) comenta a respeito desta relação entre informação e recepção virtual:

\footnotetext{
As trocas comunicacionais, ao ocorrerem em ambientes digitalizados, assumem em grande medida as principais características destes, tais como: a multiplicidade e não-linearidade das mensagens, a flexibilização do tempo e a virtualização dos relacionamentos e intercâmbios. O que temos, por consequência, é uma espécie de digitalização dos significados coletivos [...]. (CORRÊA 2009, p. 319).
}

Ao considerarmos as ponderações da autora, entendemos que, se as relações e as comunicações se desenvolvem a partir de meios digitais, então também esta troca de conhecimentos pode tornar-se mais eficiente se ocupar um lugar de destaque neste 


\section{CIÊNCIAS HUMANAS}

REVISTA DO PROGRAMA DE PÓS-GRADUAĞ̈O EM EDUCAĞ̄o

\section{(1) URI|}

meio. A constituição de significado acontece a partir deste ambiente virtualizado, que disponibiliza não somente um grande número de opções no que diz respeito aos mais diferentes conteúdos, não apenas a possibilidade interativa pela não-linearidade mas, ainda, a questão do tempo, ou seja, o conteúdo em linguagem multimídia, postado na internet, pode ser acessado a qualquer momento, em conformidade com os horários escolhidos pelo receptor da informação.

Ao considerar a importância desta tendência tecnológica e multimidiática utilizada no processo ensino-aprendizagem é que a professora titular da disciplina de literatura sul-rio-grandense do terceiro semestre do curso de Letras da Universidade Regional Integrada do Alto Uruguai e das Missões - URI, juntamente com as então mestrandas estagiárias da disciplina, propuseram à turma uma atividade envolvendo esta linguagem que abrange estas ferramentas.

Considerando os estudos de Maria João Gomes (2005) acerca da utilização de blogs como instrumento pedagógico, entendemos que se trata de uma ferramenta que evolui ao passo em que a criatividade e a imaginação são postas em questão. Desta maneira, a dinamização de um blog com vistas ao processo ensino-aprendizagem pode desenvolver diversas competências. "O desenvolvimento de competências associadas à pesquisa e selecção de informação, à produção de texto escrito, ao domínio de diversos serviços e ferramentas da web são algumas das mais valias associadas a muitos projectos de criação de blogs em contextos escolares" (GOMES, 2005, p. 313).

A partir destas considerações, a proposta das professoras da disciplina constituiu em desafiar os alunos a construir novos conhecimentos a partir de pesquisa, novas leituras e interação com o grupo seguindo um roteiro estabelecido e usando como suporte os blogs, o que simultaneamente possibilitava a inserção de tecnologias da mídia no processo formativo. Nessa perspectiva, os acadêmicos, divididos em três grupos, deveriam confeccionar blogs temáticos com o objetivo de estimular a prática da leitura justamente através da tecnologia disponível gratuitamente na internet e, ainda, a partir da comunicação realizada de forma multimídia, o que permitiria um avanço na 


\section{CIÊNCIAS HUMANAS}

REVISTA DO PROGRAMA DE PÓS-GRADUAĞ̈O EM EDUCAĞ̄o

\section{(1) URI|}

pesquisa discente sobre literatura do Rio Grande do Sul e maior familiaridade com os blogs como ferramenta de ensino e aprendizagem de literatura.

Os

blogs

"Poesia

sul-rio-grandense"

(http://poesiasulriograndense.blogspot.com.br), "Erico Verissimo em evidência" (http://ericoemevidencias.blogspot.com.br) e "O gaúcho na literatura" (http://ogauchonaliteratura.blogspot.com.br), foram atualizados no período de abril a julho de 2013, com postagens informativas e com vistas a proporcionar a interação, já que os alunos possuíam também a tarefa de postar comentários nos blogs dos colegas, para conhecer melhor o assunto abordado pelos demais estudantes e, ainda, poder expressar suas opiniões sobre os temas abordados. As três páginas da internet possuem formato de conteúdos semelhantes, já que as indicações de atividades eram as mesmas para os grupos. Apresentaremos de forma breve, os conteúdos das postagens destes blogs.

O blog "Poesia sul-rio-grandense" apresenta como objetivo da página "divulgar a Poesia Sul Rio-Grandense através de suas obras e autores, identificando temáticas, linguagens e tradições da cultura gaúcha e apresentando reflexões crítico-literárias sobre essa poesia" (2013). Encontramos dentre as primeiras postagens a seção "alguns autores da poesia sul-rio-grandense" através de texto e fotos. Além disso, o blog traz a análise do poema "Poeminha do Contra" de Mario Quintana e curiosidades sobre a poesia gaúcha. Também faz parte do conteúdo as respostas às questões: "Como a literatura riograndense se relaciona com o imaginário cultural do estado do Rio Grande do Sul?” e "Como personagens dos contos de Caio Fernando Abreu e de João Gilberto Noll podem ser inclusos nesse contexto da literatura contemporânea sulina?" que são respondidas individualmente pelas autoras do blog. Cada uma das alunas também indicou na página uma obra da literatura sul-rio-grandense, apresentando o porquê de sua leitura e a importância desta para a formação do leitor, explicando as motivações para a leitura e seus resultados. O blog conta, ainda, com um vídeo sobre Luis Fernando Verissimo, produzido pelas acadêmicas do curso.

O blog "Erico Verissimo em Evidência" apresenta como objetivo "publicar curiosidades, biografia, filmes, vídeos e depoimentos de alunos, professores e leitores 


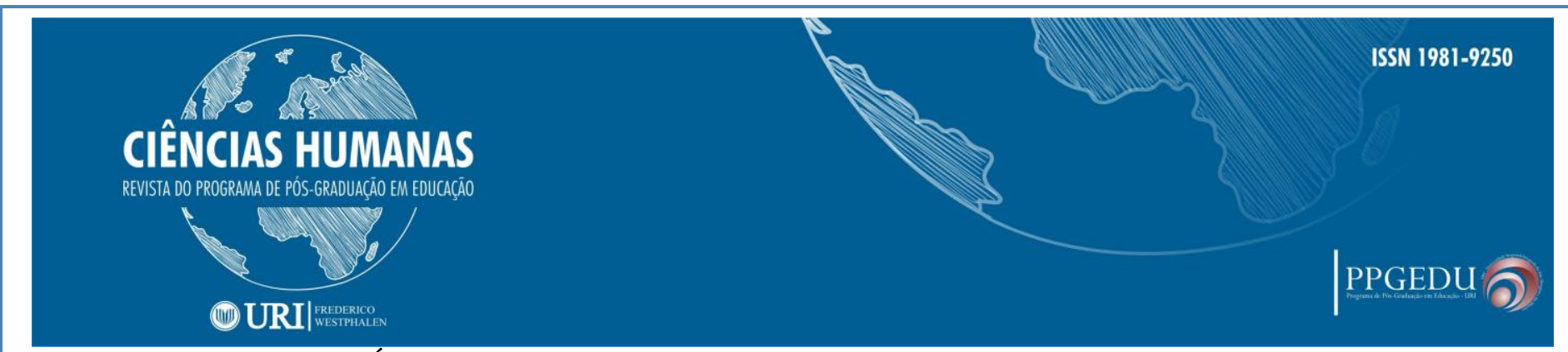

das obras de Érico Veríssimo; visando ampliar conhecimentos sobre a vida e as obras do escritor gaúcho" (2013). A proposta inicial da página traz como anseio justamente a utilização da linguagem multimidiática e da interatividade, elementos que aparecem majoritariamente no vídeo gravado pelas acadêmicas que relataram através da filmagem um pouco sobre a vida e obras do escritor gaúcho Josué Guimarães e, ainda, a partir de uma postagem de diversos vídeos, disponibilizados na internet, retratando obras do autor estudado. As acadêmicas também indicaram individualmente obras de Erico Verissimo, utilizando-se também de imagens para representar as sugestões. Ainda de forma particular, expressaram suas opiniões através da resposta à questão "Como a literatura rio-grandense se relaciona com o imaginário cultural do Estado do Rio Grande do Sul?" e ainda, "Como personagens dos contos de Caio Fernando Abreu e de João Gilberto Noll podem ser inclusos nesse contexto da literatura contemporânea sulina?”. O blog apresenta ainda a indicação individual de obras, a biografia e bibliografia do autor gaúcho e a reflexão crítica acerca da obra Olhai os lírios do campo, que contou com imagens representando os textos.

O blog "O gaúcho na literatura" tem como objetivo "apresentar a Literatura Gaúcha protagonizada por João Simões Lopes Neto e Cyro Martins”, e o faz a partir de obras dos autores, brevemente comentadas, e curiosidades acerca da vida e obra dos escritores gaúchos. Cada um dos acadêmicos também responde no blog às questões "Como a literatura rio-grandense se relaciona com o imaginário cultural do Estado do Rio Grande do Sul?" e "Como personagens dos contos de Caio Fernando Abreu e de João Gilberto Noll podem ser inclusos nesse contexto da literatura contemporânea sulina? Explique, citando exemplos”. Além disso, há sugestão de leituras, postada por cada um dos autores da página e ainda, um vídeo produzido pelos estudantes, evidenciando o tema proposto.

Dentre as tarefas, a de produção de vídeo merece atenção, uma vez que os alunos foram desafiados a construir uma videoaula, recorrendo linguagem e a texto coerentes para desenvolver os problemas propostos, explorando a linguagem visual, já que o vídeo deveria ser claro e atrativo com a participação do grupo, e valorizando a pesquisa, pois os problema propostos para construção do vídeo exigiam reflexão. 


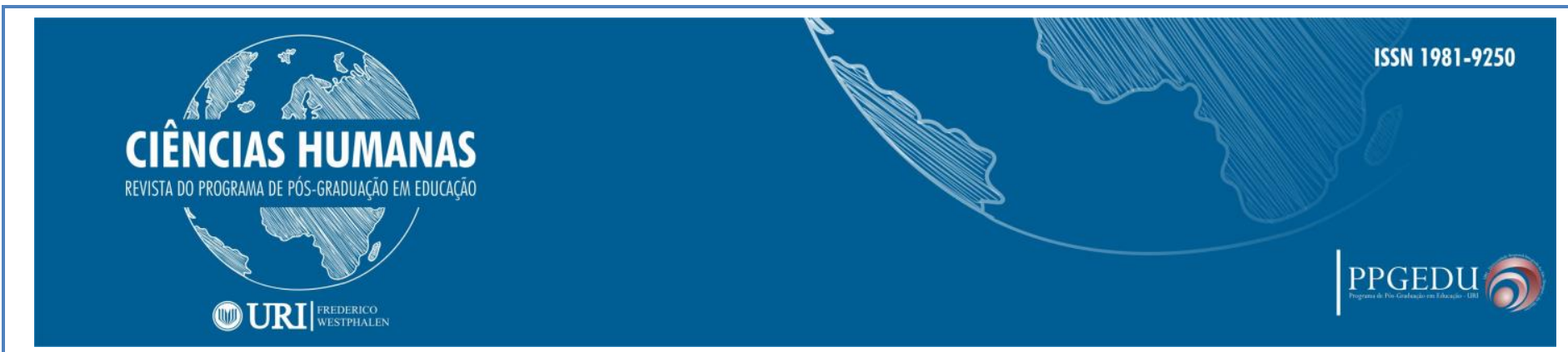

A partir dos conteúdos postados nos blogs desenvolvidos e atualizados pelos acadêmicos da disciplina, podemos concluir que os grupos atingiram os objetivos propostos em cada uma das páginas, na medida em que foi possível divulgar os temas e assuntos previamente estabelecidos, proporcionar a visão crítica através das análises e a interação por meio dos comentários e respostas individuais às questões. Ademais, a atividade cumpriu com a meta de utilizar a tecnologia disponível para tornar mais atrativo o estudo em literatura, especialmente considerando a linguagem utilizada pelos autores do blog, a multimídia, através de informações perpassadas não somente por textos, mas imagens estáticas e em movimento, republicadas de outros portais da internet além de vídeos produzidos pelos próprios autores do blog.

Esta prática representa um ganho em vários sentidos: aos acadêmicos, que aprendem, inseridos no meio tecnológico, podendo interagir com estas ferramentas e ampliando, não somente a captação do conteúdo da disciplina como, principalmente, a utilização da linguagem do meio virtual, imprescindível para professores em formação, que irão trabalhar com seus alunos imersos neste contexto tecnológico e multimidiático. Outro fator preponderante é a disponibilização de três blogs voltados à literatura, com a possibilidade de interação e divulgação de autores, obras e críticas, enfim, produção acadêmica, para difundir este conhecimento entre os internautas que podem informar-se sobre os temas de uma maneira mais atrativa.

A atividade proposta pela professora e pelas estagiárias representa uma busca por incluir a leitura e a formação de leitores no contexto tecnológico, visto que atualmente sente-se esta necessidade para que haja mais motivação por parte dos alunos em buscar conhecimento e poderá ser mais prazeroso se incluir uma ferramenta com a qual eles estão acostumados a trabalhar, a internet.

Os resultados da tarefa proposta também foram positivos em virtude do planejamento e acompanhamento aos alunos à medida em que eram sugeridas atividades desafiadoras, as quais eles deviam superar. Sem isso, dificilmente os resultados seriam satisfatórios uma vez que simplesmente apresentar uma ferramenta sem a motivação para sua utilização, possivelmente não provocaria o anseio pela busca do novo. 


\section{CIÊNCIAS HUMANAS}

REVISTA DO PROGRAMA DE PÓS-GRADUAĞ̈O EM EDUCAĞ̄o

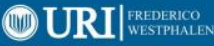

Neste sentido, Gomes (2005, p. 313) comenta que a produção exposta nos blogs torna "visível a produção escrita dos seus autores dando assim "voz" às suas ideias, interesses e pensamentos" mas que, para que haja uma audiência e estímulo à reflexão, a orientação e acompanhamento das atividades é de suma importância. Aliar tecnologia e a utilização de novas ferramentas no processo ensino-aprendizagem exige, portanto, uma postura de reconhecer o planejamento como necessário e imprescindível.

A busca por atividades diferenciadas deve nortear a prática docente, principalmente quando se trata de literatura, como é exposto por Joseane Maia no livro Literatura na formação de leitores e professores (2007). Segundo ela, o processo de ensino de línguas e literatura inspira cuidados, pois há uma "crise da leitura". Contudo, destaca que esta situação depende de como funcionará o processo de formação de leitores, do qual os maiores participantes são professor e aluno.

Nesse sentido, é necessário destacar que as atividades feitas com os alunos de Letras envolvendo o uso de diversificados instrumentos para ensino e aprendizagem também contribui na sua preparação para o exercício da carreira de professores. Eles terão uma concepção de que há outros meios que lhes servirão no sentido de promover uma educação de maior qualidade, o que pode ser comparado aos pressupostos de Joseane Maia acerca do ensino da literatura:

\footnotetext{
Embora haja uma certa unanimidade acerca do papel da família nos contatos iniciais da criança com a literatura, cabe ao Ensino Fundamental a ênfase e a continuidade do processo de formação de leitores e, finalmente, ao Ensino Médio, o fornecimento de instrumentos para que o jovem exerça plenamente a leitura crítica propriamente dita (MAIA, 2007, p. 18).
}

A criticidade acontecerá a partir do momento em que o aluno puder relacionar o que está lendo com o mundo que o cerca, com a sociedade em que está inserido, ideia que vem ao encontro do que propõe Joseane Maia (2007). A autora assevera que: “[...] a leitura é uma atividade necessária não só ao projeto educacional do indivíduo, mas também ao projeto existencial, e que, além de ser um ato que se realiza no âmbito da cognição, apresenta caráter social, histórico e político" (MAIA, 2007, p. 29).

Contudo, o hábito de ler não poderá ser despertado imediatamente nos educandos, mas à medida que eles forem instigados pelas novas ferramentas que 


\section{CIÊNCIAS HUMANAS}

REVISTA DO PROGRAMA DE PÓS-GRADUAĞ̈O EM EDUCAĞ̄o

\section{(1) URI|}

existem atualmente, poderão agregar a leitura à sua rotina de forma prazerosa e não como uma imposição feita pelo professor ou como uma atividade que gera exaustão.

E isso só será possível, de acordo com Maia (2007), se o professor de Língua Portuguesa (nas séries finais do Ensino Fundamental) ou de Literatura (no Ensino Médio) deixar de lado o uso de instrumentos "teórico-metodológicos" que estejam defasados, que já não servem mais para atrair a atenção dos alunos e pondera que:

Para o professor, a atitude de 'assumir o desafio da prática enquanto sujeito' caracteriza-se como um processo de instrumentalização permanente, o que já é tarefa bastante difícil, pois tornar-se sujeito das próprias leituras significa não fazer mais parte do jogo de simular leituras; significa, antes de tudo, fazer parte de um outro jogo - o de formar alunos-sujeitos das próprias leituras (MAIA, 2007, p. 43).

Essa reflexão da autora diz respeito ao fato de que o professor não pode se manter indiferente em relação às ferramentas diversificadas que a atualidade lhe oferece. É preciso que saiba fazer uso daquilo que faz parte do cotidiano dos alunos para chamar a sua atenção, pois desta forma os educandos se considerarão atuantes no seu próprio processo de aprendizagem, sendo ativos e não meramente aqueles que recebem informação.

Como salientam os Referenciais Curriculares do Estado do Rio Grande do Sul (2009, p.57), "leitura e texto não se referem apenas à forma escrita”. É possível utilizar imagens, vídeos, e recursos multimídia para cativar a atenção dos estudantes. Entretanto, para que os professores sejam conscientes disso, precisam trabalhar com esses recursos ainda quando estiverem sendo formados.

O tema também é discutido na tese de doutorado "Educação literária e a formação docente: encontros e desencontros do ensino de literatura na escola e na Universidade do século XXI", a autora Daniela Maria Segabinazi (2011) propõe uma reflexão a respeito da forma como deve ser realizado o ensino da literatura na universidade. Como consequência, dependendo da forma que for administrada essa disciplina no ensino superior, poderão haver reflexos positivos ou negativos nas salas de aula de ensino básico. 


\section{CIÊNCIAS HUMANAS}

REVISTA DO PROGRAMA DE PÓS-GRADUAĞ̈O EM EDUCAĞ̄o

\section{(10URI|}

Ela destaca a importância de haver observação por parte dos acadêmicos em seus estágios e também que haja um engajamento entre os conteúdos e as novas tecnologias, de forma que possam construir uma prática docente mais completa e eficiente. Do contrário, as aulas se tornam fragmentadas e podem provocar desinteresse nos alunos, principalmente quando os conteúdos não têm relação com a realidade, quando estão descontextualizados. Dessa forma, a autora assevera que é preciso investir na formação dos profissionais:

[...] formar profissionais docentes autônomos, que saibam criticamente transpor o conhecimento teórico para a situação de uso real, isto é, que ao vivenciarem durante a formação inicial experiências do cotidiano escolar e mesmo a liberdade de pesquisa e análise nos componentes curriculares possam promover em seu local de trabalho (futuro exercício profissional) planejamentos que exprimem uma prática social coerente com princípios educacionais e éticos (SEGABINAZI, 2011, p. 90).

Assim, as universidades formarão profissionais ativos que saibam trabalhar, englobando aos conteúdos curriculares, ferramentas que fazem parte do seu cotidiano e dos alunos para proporcionar um ensino de literatura mais completo e atual.

Ainda tratando do tema ensino da literatura, os autores Aldenora Márcia C. Pinheiro Carvalho e Reinaldo Portal Domingo, no artigo "As tecnologias de informação e comunicação (TIC) no ensino de literatura: uma perspectiva pós-moderna" (2012), comentam sobre a importância de incluir ferramentas que compõe o "mundo moderno" no ensino da disciplina.

Para eles, é fundamental utilizar novos meios que o contexto atual oferece, pois defendem a ideia de que: “[...] o acesso aos códigos tecnológicos pressupõe uma adequação à realidade imediata que se apresenta ao homem moderno" (CARVALHO \& DOMINGO, 2012, p. 68).

Assim, é possível inferir que cabe primeiramente ao professor universitário preparar os profissionais do futuro, que logo estarão atuando no ensino básico, para que estejam habituados a utilizar recursos que vão além da sala de aula ou da teoria que devem trabalhar. É tarefa do professor universitário buscar aprimoramento contínuo que 


\section{CIÊNCIAS HUMANAS}

REVISTA DO PROGRAMA DE PÓS-GRADUAĞ̈O EM EDUCAĞ̄o

\section{(1) URI|}

atenda às demandas de formação para que esta seja condizente com as demandas que o mercado profissional exige do recém formado. Isso implica, ao que nos parece, um longo caminho de revitalização do ensino superior com professores que, além do domínio científico, estejam preparados para uso de tecnologias e outros recursos atuais, ou seja, sejam também alfabetizados tecnologicamente.

Quando pensamos na formação de alunos nos cursos de licenciatura, essas premissas parecem ainda mais relevantes. Como podemos ensinar apenas com métodos tradicionais seculares quando temos alunos conectados, habituados a outros recursos tecnológicos? E mais essencial ainda é a questão: como fazer com que os recursos tecnológicos disponíveis, de interesse e familiaridade discente, sejam aliados no processo de ensinar e aprender? Os profissionais que atuam nas licenciaturas em geral, especialmente os professores, precisam estar atentos a esse contexto para que o ensino e a formação docente não fique em total descompasso com a realidade que os egressos dos cursos vão enfrentar ao assumir a docência da educação básica como profissão.

Nesse sentido, a atividade realizada com os acadêmicos do curso de Letras utilizando a produção dos blogs como instrumento auxiliar no processo de ensino e aprendizagem tem nos apontado algumas observações: a) apesar de ser um processo de significativa dedicação do professor, desafiado a ensinar e aprender de novas formas, é uma perspectiva promissora de qualificação do processo de formação do aluno; b) contribui de maneira fundamental para que esses futuros professores já se sintam capazes de se apropriar de recursos diversificados para incrementarem suas aulas, tornando-as mais atrativas para o perfil de aluno que os espera; c) é uma forma de integrar atividades de pesquisa às de ensino de forma gradativa e estimulante, pois o aluno entende a proposta não como uma atividade difícil, mas necessária e possível mesmo diante do contexto em que estão inseridos; d) os blogs podem constituir uma ferramenta eficiente desde que sua construção seja planejada, mediada e avaliada pelo professor com o objetivo de qualificar a formação e não vendo o blog como um fim em si mesmo; e) e ainda os blogs são suportes interessantes para dar voz aos alunos, valorizar os conhecimentos que produzem, as pesquisas que realizam e estimular formas de interação na rede. 


\section{REFERÊNCIAS}

CARVALHO A. M. C. P. \& DOMINGO, R. P. As tecnologias de informação e comunicação (TCI) no ensino de literatura: uma perspectiva pós-moderna. Revista Letras Rara, v. 1, n. 1, 2012. Disponível em:

<http://150.165.111.246/revistarepol/index.php/RLR/article/view/82/84>. Acesso em: 17 dez. 2014.

CORRÊA, Elizabeth Saad. Comunicação digital e novas mídias institucionais. In:

KUNSCH, Margarida M. Krohling (org.). Comunicação Organizacional. São Paulo: Saraiva, 2009.

ERICO Verissimo em evidência. 2013. Disponível em <

http://ericoemevidencias.blogspot.com.br/>. Acesso em: 28 jun. 2014.

FILHO, Wilson de Pádua Paula. O que é multimídia. Disponível em: <http://www.noginfo.com.br/arquivos/CC_SI_SM_T_002.pdf>. Acesso em: 28 jun. 2014.

FREITAS, A. V. ; LEITE, L. S. Capacitação de professores na sociedade contemporânea: obstáculos e desafíos. Educação em destaque, Juiz de Fora, v. 1, n. 2 , p. 01-14, 2 sem. 2008.

GOMES, Maria João. Blogs: um recurso e uma estratégia pedagógica. Anais do VII Simpósio Internacional de Informática Educativa - SIIE05, Leiria, Portugal, p. 311315, nov. 2005.

MAIA, Joseane. Literatura na formação de leitores e professores. São Paulo: Paulinas, 2007.

O gaúcho na literatura. Disponível em < http://ogauchonaliteratura.blogspot.com.br/> . 2013. Acesso em: 28 jun. 2014. 


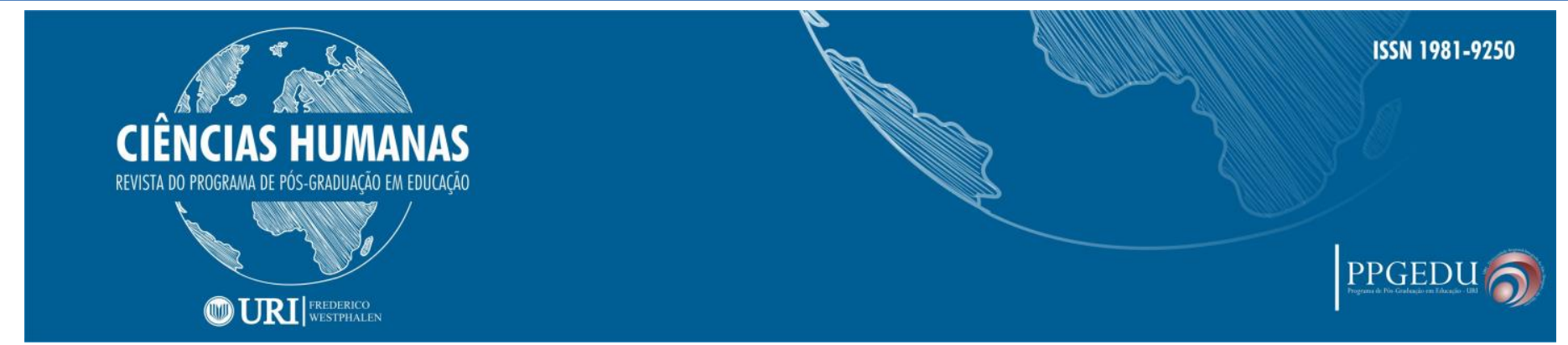

POESIA sul rio-grandense. 2013. Disponível em: <

http://poesiasulriograndense.blogspot.com.br/>. Acesso em: 28 jun. 2014.

REFERENCIAIS CURRICULARES DO ESTADO DO RIO GRANDE DO SUL:

Linguagens, códigos e suas Tecnologias/Secretaria do Estado da Educação - Porto Alegre: 2009. v.1.

SEGABINAZI, D. M. Educação literária e a formação docente: encontros e desencontros do ensino de literatura na escola e na universidade do século XXI. 2011. 275 p. Tese de Doutorado. Universidade Federal da Paraíba, João Pessoa, 2011. Disponível em:

$\langle$ http://bdtd.biblioteca.ufpb.br/tde busca/arquivo.php?codArquivo=1808 $>$. Acesso em: 17 dez. 2014. 